American Journal of Agricultural and Biological Sciences 4 (1): 79-82, 2009

ISSN 1557-4989

(C) 2009 Science Publications

\title{
Development of Microbial Inoculants and the Impact of Soil Application on Rice Seedlings Growth
}

\author{
Hayyan Ismaeil Al-Taweil, Mohammad Bin Osman, \\ Aidil Abdul Hamid and Wan Mohtar Wan Yusoff \\ Faculty Science and Technology, School of BioSciences and BioTechnology, \\ University Kebangsaan Malaysia, 43600 UKM Bangi, Selangor, Malaysia
}

\begin{abstract}
Problem statement: The present study was undertaken to assess the Empty Fruit Bunches (EFB) as carrier of Biofertilizer and microbial inoculants interaction. A study in Malaysia had shown a strain of Trichoderma viride and Bacillus megaterium were isolated from the soil. Questions were raised whether the tow inoculants compatible to be mixed in same carrier? It is important to develop delivery system of the inoculants. The present study was undertaken to assess the Empty Fruit Bunches (EFB) as carrier of biofertilizers and microbial inoculants interaction and the impact on rice seedlings. Approach: Bacillus negaterium and Trichoderma viride were grown in their respective broth culture. Cells numbers in broth pr suspension were determined. EFB powder $200 \mathrm{~g}$ in polypropylene bags was sterilized. Inoculums from broth of suspension were added in EFB using sterilized syringe, moisture level in each packet was maintained by adding respective broth, $1 \mathrm{~g}$ was periodically withdraw from fomenters, soaked in $10 \mathrm{~mL}$ sterilized distal water, then serially diluted and plated out, the number of viable cells was expressed as $\mathrm{cfu} \mathrm{g}^{-1}$ dry root. Twenty one-day-old rice seedlings of MR220 cultivar were grown under greenhouse conditions in autoclaved homogeneous soil, rice seedlings were treated with Trichoderma and Bacillus. Five replicates were used for each treatment. Rice seedlings height $(\mathrm{cm})$, root length $(\mathrm{cm})$, root numbers, root and shoot dray matter, parameters were measured during and after experiment. All data were analyzed at an alpha level of 0.05 or 0.10 using experimental design by completely randomized design model using the analysis of variance module (treatments $\times 3$ R) all treatment means were separated using Fisher's protected least significant difference (LSD) mean separation. Results: Trichoderma growth in carrier reduces Bacillus growth as interaction effect of both in same carrier which indicated that Bacillus unable to develop on multi-inoculants biofertilizers with Trichoderma. Inoculation of rice seedlings with Bacillus megaterium and Trichoderma viride produced maximum shoots and roots dry matter, increased significantly root length numbers and seedlings height comparing with control and same action of NPK fertilizers. Conclusion: The present study showed the possibility to develop the delivery system of biofertilizers which contained Bacillus and Trichoderma as mono inoculums not as multi-inoculants due to incompatible of both in same carrier. Bacillus and Trichoderma also showed appositive effect with rice seedlings.
\end{abstract}

Key words: Microbial inoculants, carrier, Bacillus, Trichoderma, empty fruit bunches

\section{INTRODUCTION}

Microorganisms have long been exploited as inoculants for plants and foodstuffs. Currently, there are numerous inoculants in the market, not only for N2 fixation and nutrient release, but also for biocontrols and bioremediations and are being produced almost all over the continents. Microbial interactions play very important roles in sustainable agriculture through the integrated nutrient supply ${ }^{[6]}$. It is important to lay major emphasis on the application of efficient microbial inoculants ${ }^{[4]}$.

Various commercial mono-culture inoculants being produced in India by various government/semi government or private agencies include: A. rhizobia and B. rhizobia, Azospirillum, Azotobacter, Bacillus megaterium, Bacillus polymyxa, mycorrhizal inoculants for forest trees and Pseudomonas as Plant Growth Promoting Rhizobacteria (PGPR) and bio control agent.

Corresponding Author: Hayyan Ismaeil Al-Taweil,School of BioSciences and BioTechnology, Faculty Science and Technology, University Kebangsaan Malaysia, 43600 UKM Bangi, Selangor, Malaysia Fax: +603-89293808 
Application of efficient inoculants of Rhizobium, Mesorhizobium and Bradyrhizobium ${ }^{[3]}$; Azospirillum; Azotobacter, Pseudomonas and phosphate solubilizing microorganisms $^{[9]}$ for the improvement of crop productivity and plant nutrition is well documented. Beneficial interactions of these biofertilizers in both legumes and cereals have been reported ${ }^{[8]}$. Trichoderma spp. Have been used for many years as antagonists in the biological control of many fungal plant diseases ${ }^{[10]}$. Trichoderma spp. have been shown to be effective for the control of both brown spot and blast diseases on rice $^{[5]}$.

It is important to develop delivery system of the inoculants. The present study was undertaken to assess the Empty Fruit Bunches (EFB) as carrier of biofertilizers and microbial inoculants interaction and the impact on rice seedlings.

\section{MATERIALS AND METHODS}

An isolate of Trichoderma viride and Bacillus megaterium was obtained from soil samples analysis in fermentation technology lab BioSciences and BioTechnologyschool (UKM).

Rice grains (MR220) were obtained from glass houses UKM.

Interaction of microbes in EFB carrier: Bacillus megaterium and Trichoderma viride were grown in their respective broth culture. Cells numbers in broth pr suspension was determined.

EFB powder $200 \mathrm{~g}$ in polypropylene bags was sterilized. onoculum from broth $\mathrm{pr}$ suspension was added in EFB using sterilized syringe, moisture level in each packet was maintained by adding respective broth.

About $1 \mathrm{~g}$ was periodically withdraw from fomenters, soaked in $10 \mathrm{~mL}$ sterilized distal water, then serially diluted and plated out, the number of viable cells was expressed as $\mathrm{cfu}^{-1}$ dry root.

Interaction of microbes with rice seedlings: Twenty one-day-old rice seedlings of MR220 cultivar were grown under greenhouse conditions in autoclaved homogeneous soil, rice seedlings were treated with Trichoderma and Bacillus. Five replicates were used for each treatment.

Plant parameters: Rice seedlings height $(\mathrm{cm})$, root length $(\mathrm{cm})$, root numbers, root and shoot dray matter, parameters were measured during and after experiment.
Statistical analyses: All data were analyzed at an alpha level of 0.05 or 0.10 using experimental design by completely randomized design model using the analysis of variance module (treatments $\times 3 \mathrm{R}$ ) all treatment means were separated using Fisher's protected Least Significant Difference (LSD) mean separation.

\section{RESULTS}

Bacillus megaterium and Trichoderma viride were being used as monoculture inoculants and being used as biofertilizers with rice seedlings.

The possibility of delivery system and interaction of these tow microbes was also explored.

Interaction of microbes in EFB carrier: The interaction of these microbes was studied in EFB carrier, which provides a convenient base to facilitate packaging and application of microbial inoculants. To develop a multi-inoculation biofertilizers, Bacillus and Trichoderma were grown separately and $20 \mathrm{~mL}$ of broth of each inoculant in $200 \mathrm{~g}$ of EFB. Microbes in different combination were used. In the monoculture, Bacillus count was $8.5 \operatorname{log~g}^{-1}$ carrier, Trichoderma was $9.0 \log \mathrm{g}^{-1}$ carrier (Table 1). When both of microbial inoculants were mixed together; invariably the counts were more that $2 * 10^{8}$ cells $\mathrm{g}^{-1}$ carrier differences in the cell numbers were statically no significant.

The EFB powder-based packets of Bacillus initially contained $8.5 * 10^{10}$ and Trichoderma initially contained $9 * 10^{10}$ but up 30 days, the number increased to 9.4 and 9.9 for Bacillus and Trichoderma respectively (Fig. 1). Co culture of Bacillus with Trichoderma affect the number of cells of Bacillus which decreased to 7.0 after 15 days and to 5.0 after 30 days, however this number was more than $2 * 10^{8}$ cells $\mathrm{g}^{-1}$ carrier, that may indicated non-compatible of mixed both inoculants at same carrier.

Table 1 interaction of EFB-Based inoculants microbes in carriers using $20 \mathrm{~mL}$ of broth inoculums.

\begin{tabular}{lllll}
\multicolumn{6}{l}{ Table 1: Log number of CFU } \\
\hline Microbial & Bacillus & Bacillus & Trichoderma & Trichoderma \\
Inoculants & 0 & 7 & 0 & 7 \\
\hline Bacillus & 9.0 & 8.6 & - & - \\
Trichoderma & - & - & 10.0 & 9.2 \\
Bacillus+ & 8.0 & 6.5 & 10.0 & 7.5 \\
Trichoderma & & & \\
\hline CD at 0.05; & Microbial & Inoculants $=\mathrm{NS}$; Interaction $=\mathrm{S}$; \\
Combinations = S; Day = NS; Initial CFU in broth culture $\mathrm{m} \mathrm{L}^{-1}$ : \\
Bacillus 8.5 Trichoderma 9.0
\end{tabular}


Am. J. Agri. \& Biol. Sci., 4 (1): 79-82, 2009

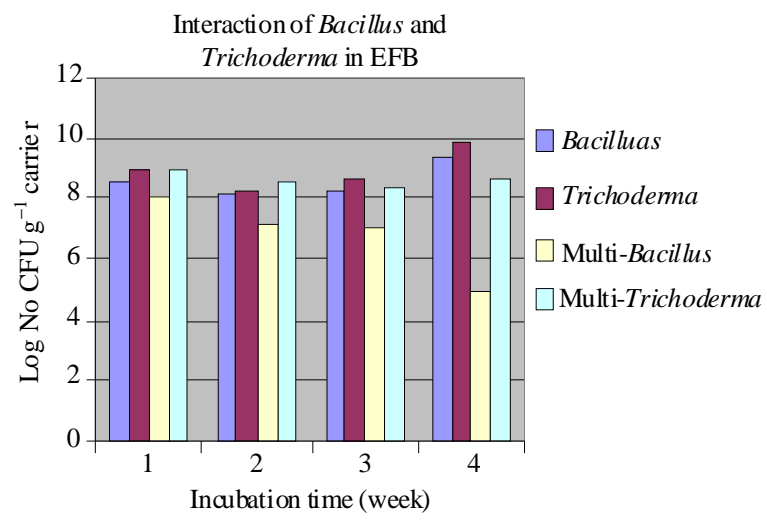

Fig. 1: Interaction of inoculants microbes in EFB

Table 2: Effect of indigenous beneficial microorganisms on rice seedlings growth

\begin{tabular}{|c|c|c|c|c|c|}
\hline Treatment & $\begin{array}{l}\text { Root length } \\
(\mathrm{cm})\end{array}$ & $\begin{array}{l}\text { Root } \\
\text { Num }\end{array}$ & $\begin{array}{l}\text { Seedlings } \\
\text { height }(\mathrm{cm})\end{array}$ & 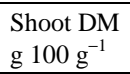 & $\begin{array}{l}\text { Root DM } \\
{\text { g } 100 \mathrm{~g}^{-1}}\end{array}$ \\
\hline Control & $8.5 \mathrm{~b}$ & $4.8 \mathrm{~b}$ & $10.0 \mathrm{~b}$ & $1.3 \mathrm{~b}$ & $0.7 \mathrm{~b}$ \\
\hline NPK & $10.5 \mathrm{a}$ & $5.8 \mathrm{a}$ & $15.0 \mathrm{a}$ & $1.8 \mathrm{a}$ & $0.9 \mathrm{a}$ \\
\hline Trichoderma & $11.0 \mathrm{a}$ & $6.0 \mathrm{a}$ & $15.5 \mathrm{a}$ & $1.8 \mathrm{a}$ & $1.0 \mathrm{a}$ \\
\hline Bacillus & $10.7 \mathrm{a}$ & $6.0 \mathrm{a}$ & $15.2 \mathrm{a}$ & $1.6 \mathrm{a}$ & $0.9 \mathrm{a}$ \\
\hline
\end{tabular}

Interaction of microbes with rice seedlings: All treatments effect significantly compare with control increasing root length and numbers, seedlings height, shoot dry matter and root dry matter for more than $20 \%$ in all parameters (Table 2) also comparing with the effect of NPK treatment which means that these treatments can be considered same chemicals effective on rice seedlings growth. The percentage of treatments difference from control was positive effect (23.5$29.4 \%)$ for root length, (20.8-25 5) root number, (50$55 \%)$ seedlings height, (23.1-38.1\%) shoot dry matter, (28.6-42.9\%) root dry matter (Table 2).

\section{DISCUSSION}

It is important to develop delivery system of the inoculants. The present study was undertaken to assess the Empty Fruit Bunches (EFB) as carrier of biofertilizers and microbial inoculants interaction and the impact on rice seedlings.

In different Combinations, determination of cell number showed that co-cultured multiple inoculants of Azospirillum, Azotobacter, Bacillus and Pseudomonas with more than $2 * 10^{8}$ cells $\mathrm{g} \mathrm{L}^{-1}$ of carrier was possible $^{[8]}$. Similarly Apte and Iswaran ${ }^{[1]}$ prepared the cultures of Rhizobium with those of Beijerinckia and Azotobacter sp.; however the ultimate counts after incubation were not determined ${ }^{[1]}$. Rice et al. ${ }^{[7]}$ also developed a co-cultured inoculant of Rhizobium and Penicillium with good viable counts.

\section{CONCLUSION}

The present study shows the possibility to develop the delivery system of Biofertilizer which contained Bacillus and Trichoderma as mono inoculums not as multi-inoculants due to incompatible of both in same carrier and that need more studies in granulation technology to produce multi inoculants as next experiments of this project. Bacillus and Trichoderma also showed appositive effect with rice seedlings which also increase the important for development the delivery system and granulation of those inoculants.

\section{ACKNOWLEDGEMENT}

The researchers thank Malaysian Agri Hi Tech Sdn Bhd for collaborated with University Kebengsaan Malaysia in project of production of Microbial Inoculants.

\section{REFERENCES}

1. Apte, R. and V. Iswaran, 1971. Cultures of Rhizobium inoculants with those of Beijerinckia and Azotobacter. Proc. Indian Natl. Sci. Acad., 40: 483-485.

http://www.new.dli.ernet.in/rawdataupload/upload/ insa/INSA_1/20005b1a_482.pdf

2. Dudeja, S.S., A.L. Khurana and L. Wati, 2000. Interaction of Azotobacter with other Beneficial Soil Microorganisms. In: Azotobacter in Sustainable Agriculture, Narula, N. (Ed.). CBS Publishers, New Delhi, pp: 95-108.

3. Dudeja, S.S. and J.S. Duhan, 2005. Biological nitrogen fixation research in pulses with special reference to mungbean and urdbean. (Forum paper). Indian J. Pulses Res., 18: 107-118. http://direct.bl.uk/bld/PlaceOrder.do?UIN=191172 406\&ETOC $=$ RN\& from $=$ searchengine

4. Elliott, L.F. and J.M. Lynch, 1995. The international workshop on establishment of microbial inocula in soils: Cooperative research project on biological resource management of the Organization for Economic Cooperation and Development (OECD). Am. J. Alt. Agric., 10: 50-73. http://library.wur.nl/WebQuery/artik/lang/875085

5. Rasmy, M.R., 1991. Studies on rice diseases in Egypt. Ph.D. Thesis, Alex University, Egypt.

6. Rengel, Z. and P. Marschner, 2005. Nutrient availability and management in the rhizosphere: Exploiting genotypic differences. New Phytol., 168: 305-312.

http://www.ncbi.nlm.nih.gov/pubmed/16219070 
7. Rice, W.A., P.E. Olsen and M.E. Leggett, 1995. Co-culture of Rhizobium meliloti and a phosphorus-solubilizing fungus (Penicillium bilaii) in sterile peat. Soil Biol. Biochem., 27: 703-705. DOI: 10.1016/0038-0717(95)98651-4

8. Saxena, A.K. and K.V.B.R. Tilak, 1994. Interaction among beneficial microorganisms. Indian J. Microbiol., 34: 91-106.

http://direct.bl.uk/bld/PlaceOrder.do?UIN=021124 072\&ETOC $=$ EN\& from=searchengine
9. Tiwari, V.N., A.N. Pathak and L.K. Lehri, 1993. Rock phosphate superphosphate in wheat in relation to inoculation with phosphate solubilizing organisms and organic waste. Indian J. Agric. Res., 27: 137-145.

10. Xu, T., G.E. Harman, Y.L. Wang and Y. Schen, 1999. Bioassay of Trichoderma harzianum: Strains for control of rice sheath blight. Phytopathology, 89: 86. 